\title{
Thomas Kahan
}

\section{Hypertension News Team}

It is my pleasure to introduce a new section to Hypertension News, which we have named Learning the ropes. To learn the ropes means to find out how to do something, learning how a particular task or job is done, to acquire an expertise. The idiom most probably is of nautical origin, where basic skills of handling the ropes on sailing ships were essential. The phrase has been known in standard English since the early 19th century, if not longer. We hope that this section will provide you with brief overviews and increase your knowledge on various topics relevant to accomplish your preclinical and/or clinical hypertension related work. Our aim is to have a translational touch. This is important, as translational research is added value for all of us, and - most importantly - to the benefit

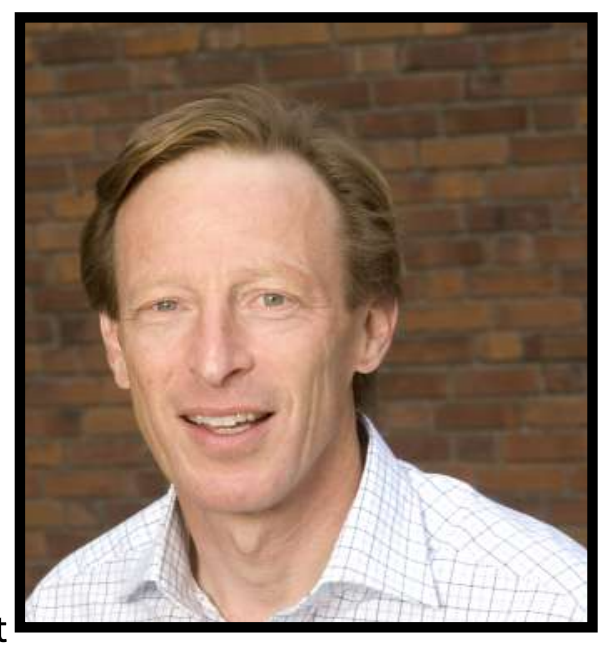
of our patients.

Much of the evidence in practised medicine is based on scientific studies. However, the results from studies addressing the same questions sometimes yield different results. There may be many reasons for this, but the ultimate challenge is to evaluate the collected results and make the right conclusions. Differences in study design may be important. Thus, treatment effects can not be safely estimated from observational data in many cardiovascular conditions, as association is not the same as causation. Also, results from observational data and uncontrolled studies may be subject to bias and confounding influence, and may be misleading [1,2]. This generally requires the findings from observational studies to be confirmed by properly designed randomized controlled studies. Having said that, however, randomized trials may be of a limited role when establishing the effectiveness of procedural interventions, where there are considerable barriers to conducting and implementing randomized controlled studies [3].

A systematic literature overview and meta-analysis is one way to strengthen the findings obtained from individual studies, in particular if those studies were of limited size or inconclusive, or if the studies yielded conflicting results. Whether studies with different design can be combined or not in such analyses is a matter of debate. Meta-analyses are sometimes considered to provide the strongest level of evidence, while others consider them misleading [4,5]. Thus, we considered it appropriate to start this new section Learning the ropes with three contributions on the potential difficulties in designing, performing, and interpreting meta-analyses; and more specifically in the context of blood pressure lowering therapy.

\section{References}

1. Rush CJ, Campbell RT, Jhund PS et al. Association is not causation: treatment effects cannot be estimated from observational data in heart failure. Eur Heart J 2018;39:3417-3438. doi: 10.1093/eurheartj/ehy407

2. Vonbank A, Drexel H, Agewall S, et al. Reasons for disparity in statin adherence rates between clinical trials and real-world observations: a review. Eur Heart ] Cardiovasc Pharmacother 2018;4:230-236. doi: 10.1093/ehjcvp/pvy028.

3. Wallis CJD, Detsky AS, Fan E. Establishing the effectiveness of procedural interventions: The limited role of randomized trials. JAMA. 2018 Nov 1. doi: 10.1001/jama.2018.16329. [Epub ahead of print]

4. Packer M. Are meta-analyses a form of medical fake news? Thoughts about how they should contribute to medical science and practice. Circulation. 2017;136:2097-2099. doi: 10.1161/CIRCULATIONAHA.117.030209.

5. Björk S, Manhem K, Reosengren A, et al. Meta-analyses and blood pressure goals. J Clin Hypertens (Greenwich). 2018 Jun 26. doi: 10.1111/jch.13327. [Epub ahead of print] 